\title{
MALDI Linear-Field Reflectron TOF Post-Source Decay Analysis of Underivatized Oligosaccharides: Determination of Glycosidic Linkages and Anomeric Configurations Using Anion Attachment
}

\author{
Bing Guan and Richard B. Cole \\ Department of Chemistry, University of New Orleans, New Orleans, Louisiana, USA
}

\begin{abstract}
Six different anionic species (fluoride, chloride, bromide, iodide, nitrate, and acetate) are tested for their abilities to form anionic adducts with neutral oligosaccharides that are detectable by MALDI-TOF mass spectrometry. Fluoride and acetate cannot form anionic adducts with the oligosaccharides in significant yields. However, bromide, iodide, and nitrate anionic adducts consistently appear in higher abundances relative to $\left[\mathrm{M}-\mathrm{H}^{-}\right.$, just like the highly stable chloride adducts. Post-source decay (PSD) decompositions of $\mathrm{Br}^{-}, \mathrm{I}^{-}$, and $\mathrm{NO}_{3}{ }^{-}$adducts of oligosaccharides provide no structural information, i.e., they yield the respective anions as the main product ions. However, determination of linkage types is achieved by analysis of structurally-informative diagnostic peaks offered by negative ion PSD spectra of chloride adducts of oligosaccharides, whereas the relative peak intensities of pairs of diagnostic fragment ions allow differentiation of anomeric configurations of glycosidic bonds. Thus, simultaneous identification of the linkage types and anomeric configurations of glycosidic bonds is achieved. Our data indicate that negative ion PSD fragmentation patterns of chloride adducts of oligosaccharides are mainly determined by the linkage types. Correlation may exist between the linkage positions and fragmentation mechanisms and/or steric requirements for both cross-ring and glycosidic bond fragmentations. PSD of the chloride adducts of saccharides containing a terminal Glc $\alpha 1-2 F r u$ linkage also yields chlorine-containing fragment ions which appear to be specifically diagnostic for a fructose linked at the 2-position on the reducing end. This also allows differentiation from saccharides with a 1-1 linked pyranose on the same position. (J Am Soc Mass Spectrom 2008, 19, 1119-1131) (C) 2008 American Society for Mass Spectrometry
\end{abstract}

$\mathrm{F}$ ollowing the advances in proteomics, there is a growing interest in the importance of glycomics, i.e., the study of the breadth of sugar forms (structure and function of glycans) in biological organisms. Carbohydrates (or saccharides) are the most abundant biological compounds found on earth. They are well known as energy reservoirs and structural materials in cell walls. However, it has become clear that oligosaccharides and glycoconjugates (e.g., glycoproteins and glycolipids) serve as crucial mediators for a wide variety of complex cellular events [1]. Carbohydrates also play an important role in specific molecular recognition, protein folding, stability, and pharmacokinetics due to their great structural diversity. Moreover, glycosylation is a ubiquitous form of post-translational modification to both proteins and lipids.

Address reprint requests to Dr. Richard B. Cole, Department of Chemistry, University of New Orleans, 2000 Lakeshore Drive, New Orleans, LA 70148, USA. E-mail: rcole@uno.edu
Gaining a clear understanding of the crucial biological roles of oligosaccharides requires complete structural characterization of carbohydrates or glycoconjugates, which includes determinations of the numbers and types of monosaccharide units, ring substituents, sequences, branching, linkage positions, and anomeric configurations between adjacent monosaccharide units. In most cases, merely knowing the monosaccharide sequence is inadequate; thus, unambiguous differentiation of both linkage positions and anomeric configurations represents an essential aspect of the fine stereochemical analysis of oligosaccharides.

Mass spectrometry (MS) has emerged as an important technique for structural analysis of oligosaccharides [2], offering certain advantages such as lower sample consumption, higher sensitivity, shorter acquisition times, and less stringent sample purity requirements as compared, for example, to NMR analysis. Anomers and linkage isomers that have identical masses cannot be easily distinguished in mass spectrometry, but to aid in this endeavor, separation steps 
are often performed before mass spectrometric identification. Nevertheless, MS does have the capability to differentiate underivatized saccharide stereoisomers as demonstrated when coupled with several different desorption/ionization techniques such as field desorption (FD) [3, 4], laser desorption (LD) [5, 6], fast atom bombardment (FAB) [7-17], liquid secondary ion mass spectrometry (LSIMS) [18, 19], and electrospray (ES) [20-25].

Matrix-assisted laser desorption/ionization mass spectrometry (MALDI-MS) has become established as a powerful tool to characterize carbohydrates [26-28]. Although the majority of mass spectral analyses of neutral saccharides are performed in the positive mode via adduct formation with $\mathrm{H}^{+}$or with metal cations, a potential limitation for positive ion MALDI analysis is that facile decomposition and nonspecific cleavages are often induced for certain unstable alkali metal ion adducts [29, 30]. Moreover, the inability to simultaneously analyze neutral and acidic oligosaccharides for MALDI in the positive ion mode is also a noteworthy drawback.

The above limitations potentially can be resolved by using negative ion mode MALDI MS analysis of oligosaccharides, which has been gaining popularity after a series of $\beta$-carboline compounds, e.g., harmane, nonharmane, and harmine, were introduced as efficient MALDI matrixes [31-33]. The tendencies for fucosylated oligosaccharides to lose fucose and for sialylated oligosaccharides to lose sialic acid, as seen in most positive ion MALDI spectra, are not as apparent in negative ion mode analysis [34]. In addition, the acidic oligosaccharides, which readily ionize as $[\mathrm{M}-\mathrm{H}]^{-}$ anions, can be far more amenable to detection in negative mode MALDI analysis than in positive mode. However, unlike acidic oligosaccharides, neutral oligosaccharides exhibit a much lower tendency to deprotonate, rendering the $[\mathrm{M}-\mathrm{H}]^{-}$signal intensity generally lower.

Anion attachment represents a promising alternative method to enable charging of neutral saccharides in negative ion MALDI-MS using $\beta$-carboline compounds as the MALDI matrix, and structurally informative fragments were readily produced by decompositions of $\left[\mathrm{M}+\mathrm{HSO}_{4}-\mathrm{H}_{2} \mathrm{O}\right]^{-}[34]$ and $[\mathrm{M}+\mathrm{Cl}]^{-}$[35-38]. Although not truly tandem MS, post-source decay (PSD) can provide valuable information about the structures of gas-phase ions generated by MALDI [39, 40]. When subjected to PSD fragmentation in the positive ion mode, linkage isomers of saccharides are not readily distinguished based upon the PSD spectral patterns because saccharides are frequently cleaved at the glycosyl linkages and more specific cross-ring cleavage ions are often of rather low abundance in positive mode PSD [27, 41, 42]. On the contrary, when subjected to PSD fragmentation in the negative ion mode, prominent cross-ring cleavages are usually produced along with glycosyl bond cleavages. PSD of both deprotonated molecules and anionic adducts of oligosaccharides has been performed and some success for differ- entiation of linkage positions as well as anomeric configurations in oligosaccharides has been shown [3538, 43-45].

Recent studies in negative ES-MS have established that more than a dozen stable anionic adducts of carbohydrates (anion attachment) can be observed in the gas phase, and some of these anionic adducts could offer structural information upon CID [24, 46-49]. But the corresponding studies of anion attachment of oligosaccharides in negative ion mode MALDI-MS have not been systematically exploited [34-38]. The current study focuses on studying the PSD fragmentation patterns of MALDI-generated anionic adducts of oligosaccharides. A series of anions is tested and the ability to form anionic adducts with saccharides of varying sizes is compared in MALDI reflectron time-of-flight (rTOF) MS. Moreover, PSD patterns of the investigated adducts are evaluated for their abilities to yield structurallyinformative fragments. Our goal is to document the effects of linkage positions and anomeric configurations of neutral oligosaccharides on the PSD patterns of their anionic adducts. We evaluate the application of anion attachment with PSD in MALDI linear-field reflectron TOF MS not only as a technique to determine linkage positions, but also to differentiate anomeric configurations in underivatized oligosaccharides.

\section{Experimental}

\section{Chemicals}

All neutral oligosaccharides were purchased from Sigma Chemical Co. (St. Louis, MO) and prepared at 1 $\mathrm{mM}$ in a solution of 4:1 methanol/water. D-glucuronic acid was purchased from Aldrich (Milwaukee, WI) and prepared at $1 \mathrm{mM}$ in a 4:1 solution of methanol/water. Hydrochloric acid, acetic acid, ammonium nitrate, ammonium fluoride, ammonium chloride, ammonium bromide, ammonium iodide and ammonium acetate were obtained from Aldrich and were prepared at 1 $\mathrm{mM}$ in a solution of 4:1 methanol/water. Harmine and harmine hydrochloride were also purchased from Aldrich. Both matrixes were prepared at $20 \mathrm{mg} / \mathrm{mL}$ in a solution of 4:1 methanol/water. All chemicals were used as received without further purification.

\section{Mass Spectrometry}

Mass spectra were acquired on an Applied Biosystems Voyager Elite MALDI-TOF mass spectrometer equipped with delayed extraction (Applied Biosystems, Framingham, MA) and a pulsed $\mathrm{N}_{2}$ laser $(\lambda=337 \mathrm{~nm})$; an extraction voltage of $20 \mathrm{kV}$ was typically employed. All mass spectra were acquired in the negative reflectron mode employing delayed extraction with the laser intensity adjusted to just above the threshold energy for appearance of oligosaccharide anionic adducts. When acquiring PSD spectra, laser intensity was adjusted to $10 \%-30 \%$ above this threshold, and the mirror ratios in 
the PSD segment list were manually calculated and specified such that the targeted ions in question would be focused and collected within the same PSD segment. All mass spectra and PSD spectra consist of an average of 50-100 laser shots. Reported $\mathrm{m} / \mathrm{z}$ values show nominal masses only (i.e., values after the decimal places have been truncated). The instrument was externally calibrated by monoisotopic peaks of anionic dopants, harmine matrix, and oligosaccharides. Data processing was performed using IGOR Pro 4.07 (Wave Metrics Inc., Lake Oswego, OR).

MALDI samples were prepared using an optimized "thin-layer" [50,51] method. Corresponding ammonium salts were used when investigating six different anionic species, i.e., acetate, fluoride, chloride, bromide, iodide, and nitrate anions, for their abilities to yield anionic adducts of oligosaccharides in MALDI. First, 2 $\mu \mathrm{L}$ of $1 \mathrm{mM}$ ammonium salt solution, $2 \mu \mathrm{L}$ of $1 \mathrm{mM}$ acid, and $4 \mu \mathrm{L}$ of harmine matrix solution (all in 4:1 methanol/water) were mixed. Next, a $0.5 \mu \mathrm{L}$ aliquot of this final matrix solution was deposited onto a sample plate and dried to form the matrix layer; $0.5 \mu \mathrm{L}$ of oligosaccharide solution was then deposited on top of the matrix layer and allowed to dry. Acidic conditions were used as indicated above because harmine works best as a MALDI matrix at low $\mathrm{pH}$ [34]. Therefore, in addition to the ammonium salts that were added in every case, $1 \mathrm{mM} \mathrm{HCl}$ in a 4:1 solution of methanol/ water was used when testing chloride anion, whereas 1 $\mathrm{mM} \mathrm{HNO}$ was used when testing nitrate anion. For all the other ions, i.e., acetate, fluoride, bromide, and iodide anions, $5 \%$ acetic acid in a $4: 1$ solution of methanol/water was used during sample preparation. Acetic acid was chosen because it does not form acetate adducts with the tested oligosaccharides (see the Results section below), which might complicate the interpretation of results. PSD experiments were performed on stable anionic adducts (i.e., $\mathrm{Cl}^{-}, \mathrm{Br}^{-}, \mathrm{I}^{-}$, and $\mathrm{NO}_{3}{ }^{-}$) of oligosaccharides.

\section{Results and Discussion}

\section{Comparison of Anionic Adducts of Neutral and Acidic Oligosaccharides}

Of the six anionic species studied, nitrate, chloride, bromide, and iodide were able to form anionic adducts with a series of neutral and acidic oligosaccharides in MALDI-TOF MS (Table 1) (11, 25, 28, 31-35), from monosaccharides such as $\alpha$-D-glucose (31) to larger oligosaccharides such as $\gamma$-cyclodextrin (34). By contrast, anionic adducts of oligosaccharides were not observed to form for fluoride and acetate in this study. When serving as the attaching anions to smaller saccharides (monosaccharides, disaccharides and trisaccharides) in negative ion MALDI, nitrate, chloride, bromide, and iodide appear to have an advantage over bisulfate which reportedly only forms adducts with tetrasaccharides or larger oligosaccharides [34].
Table 1. List of saccharides analyzed by PSD of corresponding anionic adducts

\begin{tabular}{|c|c|c|}
\hline No. & Formula & Name \\
\hline 1 & Glc $\beta 1-6 \mathrm{Glc}$ & Gentiobiose \\
\hline 2 & Glc $\alpha 1-6 \mathrm{Glc}$ & Isomaltose \\
\hline 3 & $\mathrm{Glc} \beta 1-4 \mathrm{Glc}$ & Cellobiose \\
\hline 4 & Glc $\alpha 1-4 \mathrm{Glc}$ & Maltose \\
\hline 5 & Glc $\beta 1-3 \mathrm{Glc}$ & Laminaribiose \\
\hline 6 & Glc $\alpha 1-3 \mathrm{Glc}$ & Nigerose \\
\hline 7 & GIc $\beta 1-2 \mathrm{Glc}$ & Sophorose \\
\hline 8 & Glc $\alpha 1-2 \mathrm{Glc}$ & Kojibiose \\
\hline 9 & Glc $\alpha 1-1 \beta \mathrm{Glc}$ & $\alpha, \beta$-Trehalose \\
\hline 10 & Gal $\beta 1-6 \mathrm{Gal}$ & \\
\hline 11 & Gal $\alpha 1-6 \mathrm{Glc}$ & Melibiose \\
\hline 12 & Man $\alpha 1-6$ Man & \\
\hline 13 & Gal $\beta 1-4 G l c$ & Lactose \\
\hline 14 & Gal $\beta 1-4$ Man & Epilactose \\
\hline 15 & Gal $\beta 1-4 \mathrm{Gal}$ & \\
\hline 16 & Gal $\alpha 1-4 \mathrm{Gal}$ & \\
\hline 17 & Man $\alpha 1-3$ Man & \\
\hline 18 & Man $\alpha 1-2 M a n$ & \\
\hline 19 & Glc $\alpha 1-6$ Fru & Palatinose \\
\hline 20 & Glc $\beta 1-4 F r u$ & Lactulose \\
\hline 21 & Glc $\alpha 1-3 F r u$ & Turanose \\
\hline 22 & Glc $\alpha 1-2$ Fru & Sucrose \\
\hline 23 & Gal $\beta 1-3 A r a$ & \\
\hline 24 & Gal $\alpha 1-6 \mathrm{Glc} \alpha 1-2 \mathrm{Fru}$ & Raffinose \\
\hline 25 & Gal $\alpha 1-6$ Gal $\alpha 1-6 \mathrm{Gl} \alpha \alpha 1-2$ Fru & Stachyose \\
\hline 26 & Glc $\alpha 1-6 \mathrm{Glc} \alpha 1-6 \mathrm{Glc}$ & Isomaltotrisoe \\
\hline 27 & Glc $\beta 1-4 \mathrm{Glc} \beta 1-4 \mathrm{Glc}$ & Cellotriose \\
\hline 28 & Glc $\alpha 1-4 \mathrm{Glc} \alpha 1-4 \mathrm{Glc}$ & Maltotriose \\
\hline 29 & Glc $\alpha 1-6 \mathrm{Glc} \alpha 1-4 \mathrm{Glc}$ & Panose \\
\hline 30 & Gal $\alpha 1-3 \mathrm{Gal} \beta 1-4 \mathrm{Gal} \alpha 1-3 \mathrm{Gal}$ & $3 \alpha, 4 \beta, 3 \alpha$-Galactotetraose \\
\hline 31 & & Glucose \\
\hline 32 & & $\alpha$-Cyclodextrin \\
\hline 33 & & $\beta$-Cyclodextrin \\
\hline 34 & & $\gamma$-Cyclodextrin \\
\hline 35 & & Glucuronic acid \\
\hline
\end{tabular}

The gas-phase basicity (GB) of the anion clearly plays an important role for the successful observation of anionic adducts in MALDI MS. The gas-phase basicity of the deprotonated matrix, [harmine $-\mathrm{H}^{-}$(between 1373 and $1407 \mathrm{~kJ} / \mathrm{mol}$ ) [35] is lower than that of fluoride $(1529 \mathrm{~kJ} / \mathrm{mol})$ and acetate $(1427 \mathrm{~kJ} / \mathrm{mol})$, but higher than that of nitrate (GB $1329.7 \mathrm{~kJ} / \mathrm{mol}$ ), chloride (GB $1372.8 \mathrm{~kJ} / \mathrm{mol}$ ), bromide (GB $1331.8 \mathrm{~kJ} / \mathrm{mol}$ ), and iodide (GB $1293.7 \pm 0.84 \mathrm{~kJ} / \mathrm{mol}$ ). This is in agreement with our previous finding that the gas-phase basicity of an anion must be lower than that of [matrix $-\mathrm{H}]^{-}$to form anionic adducts with a neutral analyte in high abundance [35]. Also, it appears that $\mathrm{Cl}^{-}$gives the strongest adduct signal among all the anions investigated because the gas-phase basicities of saccharides and chloride are closest [52].

D-glucuronic acid (35), an acidic saccharide containing one carboxylic acid moiety, can also form adducts with nitrate $(\mathrm{m} / \mathrm{z} 256)$, chloride $(\mathrm{m} / \mathrm{z} 229,231)$, bromide $(\mathrm{m} / \mathrm{z} 273,275)$, and iodide $(\mathrm{m} / \mathrm{z} 321)$ (Figure 1a) in MALDI-MS. In all cases, an intense peak corresponding to $[\mathrm{M}-\mathrm{H}]^{-}(\mathrm{m} / \mathrm{z}$ 193) is observed in addition to the respective adduct peaks. Compared with the neutral 

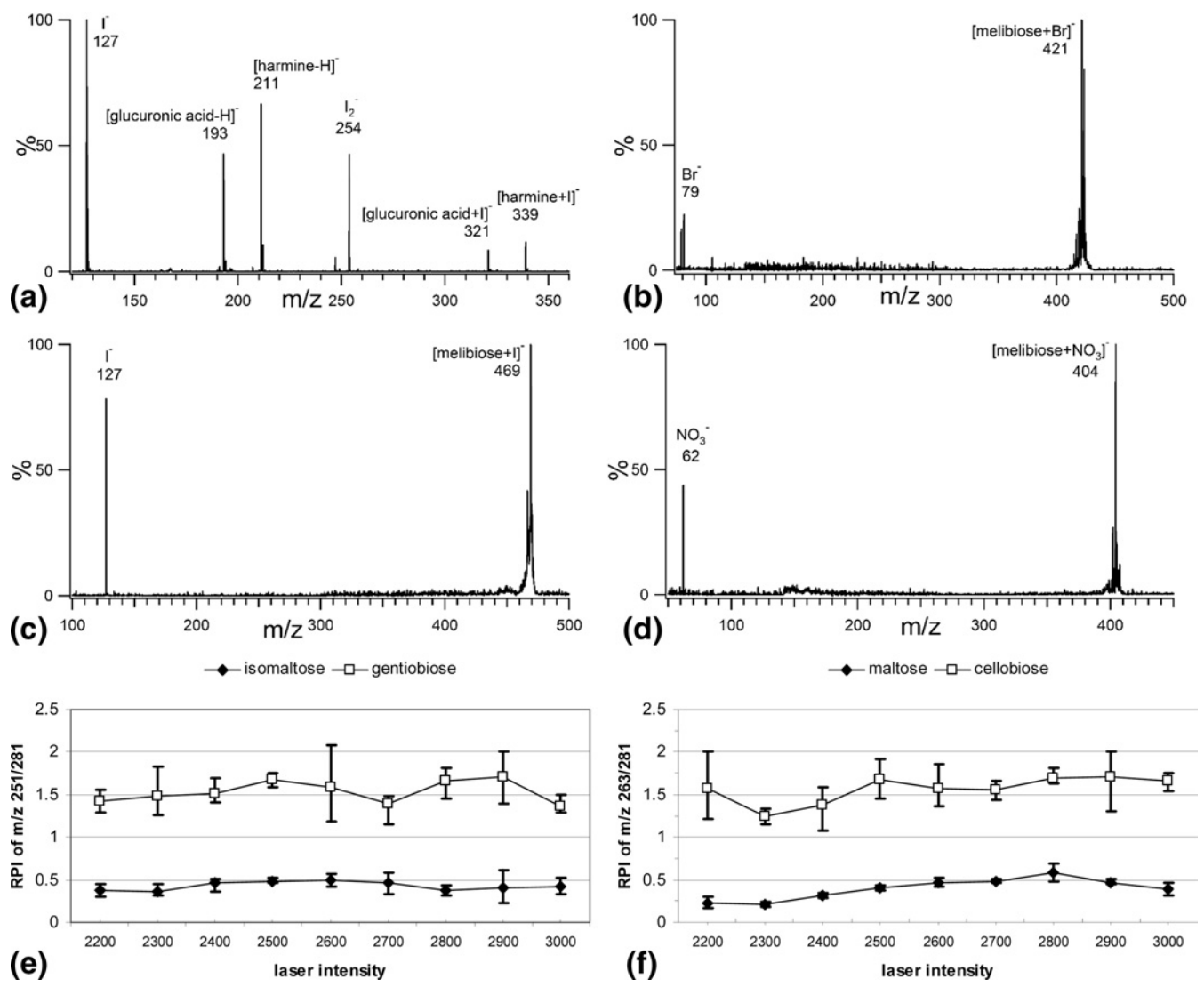

Figure 1. (a) MALDI-TOF mass spectrum of iodide adducts of glucuronic acid. Both [glucuronic acid $-\mathrm{H}]^{-}$at $\mathrm{m} / \mathrm{z} 193$ and [glucuronic acid $\left.+\mathrm{I}\right]^{-}$at $\mathrm{m} / \mathrm{z} 321$ are formed.; PSD of: (b) bromide; (c) iodide; and (d) nitrate adducts of melibiose yield $\mathrm{Br}^{-}, \mathrm{I}^{-}$, and $\mathrm{NO}_{3}{ }^{-}$, respectively, without structurally-informative disaccharide fragments. Relative peak intensities (RPIs) as a function of laser intensity: (e) RPI of $m / z 251$ versus $m / z 281$ in 1-6 linked disaccharides; (f) RPI of $m / z 263$ versus $\mathrm{m} / \mathrm{z}$ 281 in 1-4 linked disaccharides. RPI in each pair is calculated with peak intensity of $\mathrm{m} / \mathrm{z} 281$ normalized to $100 \%$. Subtle variations in the PSD experiments are inevitable, but the RPI is fairly stable regardless of laser intensity. Error bars show the standard deviation of four measurements.

sugars, acidic oligosaccharides generally produce stronger signals, and deprotonation of the latter occurs more readily than anion attachment. Nitrate, chloride, bromide, and iodide can serve as good candidates for simultaneous detection of intact neutral and acidic oligosaccharides in the negative ion mode since neutral and acidic oligosaccharides often coexist as mixtures in carbohydrates from biological sources.

For all four anions (i.e., chloride, bromide, iodide, and nitrate) that form observable adducts with melibiose (11), PSD of [melibiose + anion] ${ }^{-}$was performed to see whether structurally-informative fragments could be obtained. PSD of [melibiose $+\mathrm{Br}]^{-}$(Figure 1b), [melibiose $+\mathrm{I}^{-}$(Figure 1c) and [melibiose $\left.+\mathrm{NO}_{3}\right]^{-}$ (Figure 1d) produce $\mathrm{Br}^{-}, \mathrm{I}^{-}$, and $\mathrm{NO}_{3}{ }^{-}$as the sole major product ion, respectively; hence, structural information of saccharides is not obtained. In contrast, structurallyinformative sugar fragments are observed upon PSD of [melibiose $+\mathrm{Cl}^{-}$(Figure 2d). The PSD decomposition patterns can be explained by considering that $[\mathrm{M}-\mathrm{H}]^{-}$ ions of disaccharides often have gas-phase basicities close to that of chloride, but substantially higher than those of nitrate, bromide, and iodide. Unlike chloride, the weak attraction of nitrate, bromide, and iodide for protons cannot compete with the pull of the alkoxide site on the disaccharide upon PSD, leading to loss of the anion and thus leaving the neutral disaccharide while producing no structurally-informative disaccharide fragments. Chloride thus remains a preferred anion for structural determination employing anion attachment followed by PSD using MALDI-TOF [35] and is thereby used hereafter in this study for PSD experiments.

\section{Linkage and Anomeric Configuration Differentiation by PSD of [Disaccharides $+\mathrm{Cl}^{-}$}

The current investigation builds upon a previous MALDI-TOF MS study [53] where only a limited number of glucopyranosyl glucoses disaccharides (six) were evaluated for their PSD behavior. To further exploit the chloride attachment approach for carbohydrate analysis, we extend our investigation to now include five 1-6 linked (Figure 2), six 1-4 linked (Figure 3), and three 

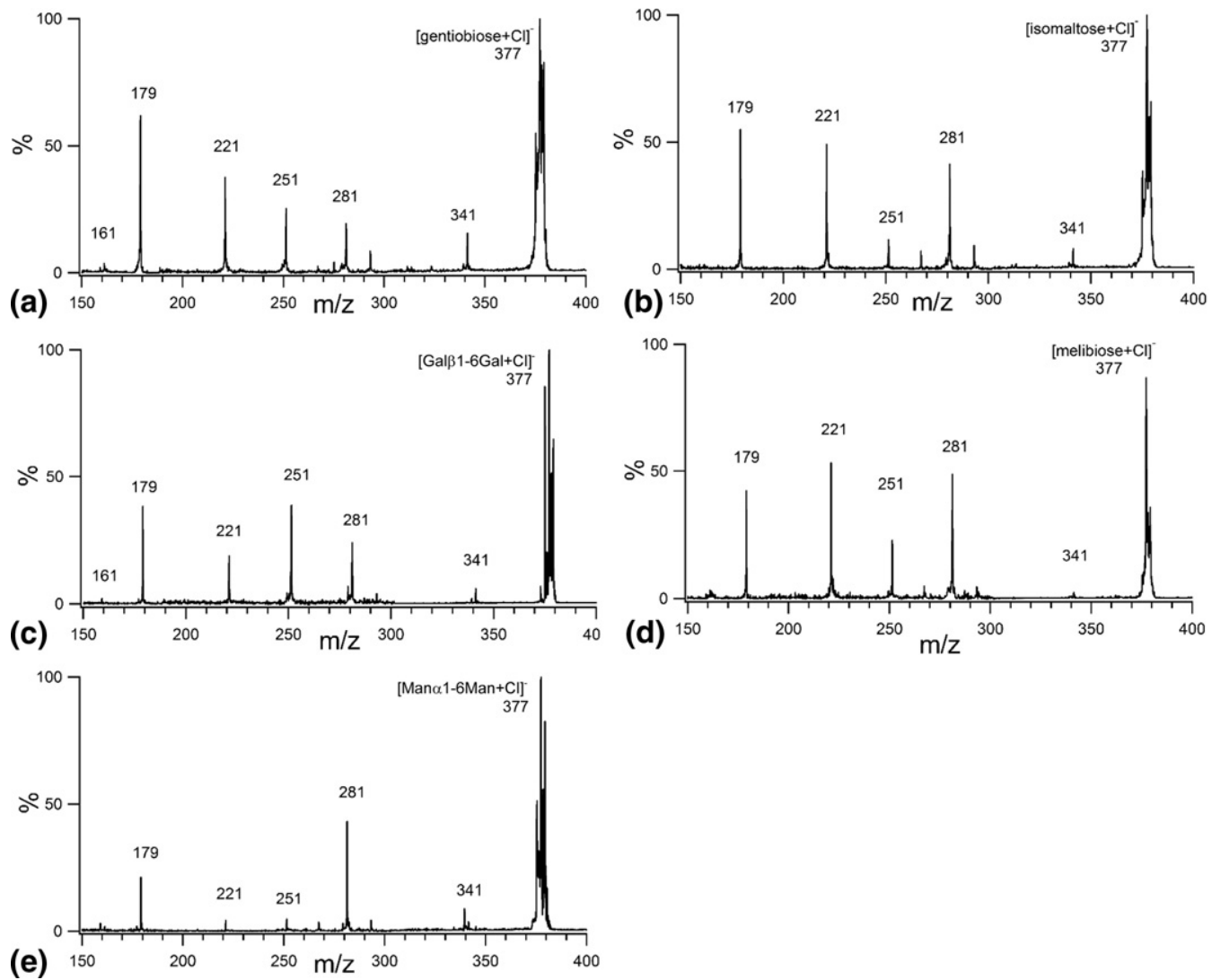

Figure 2. Negative ion PSD of chloride adducts of 1-6 linked disaccharides. (a) gentiobiose (Glc $\beta 1-6 \mathrm{Glc}) ;(\mathbf{b})$ isomaltose (Glc $\alpha 1-6 \mathrm{Glc}) ;(\mathbf{c}) \mathrm{Gal} \beta 1-6 \mathrm{Gal}$; (d) melibiose (Gal $\alpha 1-6 \mathrm{Glc})$; and (e) Man $\alpha 1$ 6Man. The $\alpha$ - (isomaltose) and $\beta$-configuration (gentiobiose) in 1-6 linked glucopyranosyl disaccharides can be readily differentiated by examining whether the relative abundance ratio of $\mathrm{m} / \mathrm{z} 251: 281$ is larger than unity ( $\beta$ isomer) (Figure $2 a$ ) or smaller than unity ( $\alpha$ isomer) (Figure $2 b$ ). This peak intensity difference is also applicable to other $1-6$ linked disaccharides.

1-3 linked (Figure 4a, b, d) hexose-hexose disaccharides. We further expand the study to include three hexose-hexose disaccharides with a 1-2 linkage (Figure $4 \mathrm{e}, \mathrm{f})$ and one with a 1-1 linkage (Figure 4c). Among this total are a variety of pyranose-pyranose disaccharides with at least one pyranose other than glucose (1-6 linkage: Figure 2c, d, e; 1-4 linkage: Figure 3c, d, e, f; 1-3 linkage: Figure 4d; and 1-2 linkage: Figure 4h). In addition to considering linkage position, the disaccharides can be divided into four groups based upon constituent monosaccharides (Table 1): (1) nine glucopyranosyl glucoses (1-9); (2) nine pyranose-pyranose disaccharides with at least one hexose other than glucose (10-18); (3) three glucopyranosyl fructoses plus one galactopyranosyl fructose (19-22); and (4) one hexose-pentose disaccharide (23). The negative ion MALDI mass spectra of the disaccharides (Table 1, 1-22) all show peaks at $m / z 377\left(\left[\mathrm{M}+\mathrm{Cl}^{-}\right)\right.$except for $\mathrm{Gal} \beta 1-$ 3Ara (23) where the $[\mathrm{M}+\mathrm{Cl}]^{-}$peak appears at $\mathrm{m} / \mathrm{z} 347$.

The major neutral losses observed in the PSD spectra of chloride adducts of five 1-6 linked disaccharides (Figure 2a-e), six 1-4 linked (Figures 3a-f), three 1-3 linked (Figure 4a, b, d), and three 1-2 linked (Figure 4e, $\mathrm{f}, \mathrm{h}$ ) disaccharides all show a certain degree of unifor- mity (Table 2). For this set of $[\mathrm{M}+\mathrm{Cl}]^{-}$compounds, because the diagnostic neutral losses for disaccharides with the same linkages remain virtually unchanged no matter how the reducing end or the nonreducing end vary, it is fairly safe to conclude that the negative ion PSD fragmentation patterns of chloride adducts of disaccharides are characteristic of the glycosidic linkage positions between adjacent monosaccharide units, independent of the constituent pyranose and the anomeric configurations.

The characteristic PSD fragmentation patterns for each linkage position can be summarized by stating that observation of the PSD fragments $[\mathrm{M}-\mathrm{H}-162]^{-}$, $[\mathrm{M}-\mathrm{H}-120]^{-},[\mathrm{M}-\mathrm{H}-90]^{-}$, and $[\mathrm{M}-\mathrm{H}-60]^{-}$ with the absence of $[\mathrm{M}-\mathrm{H}-78]^{-}$are characteristic of the 1-6 linked disaccharides (Figure 2a-e; Table 2). Appearance of the PSD fragment peaks of $[\mathrm{M}-\mathrm{H}-$ $180]^{-},[\mathrm{M}-\mathrm{H}-162]^{-},[\mathrm{M}-\mathrm{H}-78]^{-}$and $[\mathrm{M}-\mathrm{H}-$ $60]^{-}$with the absence of $[\mathrm{M}-\mathrm{H}-90]^{-}$are indicative of the 1-4 linked disaccharides (Figure 3a-f; Table 2). Observation of the PSD fragmentation pathways producing $[\mathrm{M}-\mathrm{H}-180]^{-}$and $[\mathrm{M}-\mathrm{H}-162]^{-}$, as well as the low abundance $[\mathrm{M}-\mathrm{H}-120]^{-}$, appears to be the pattern for the 1-3 linked disaccharides (Figure 4a, b, d; 

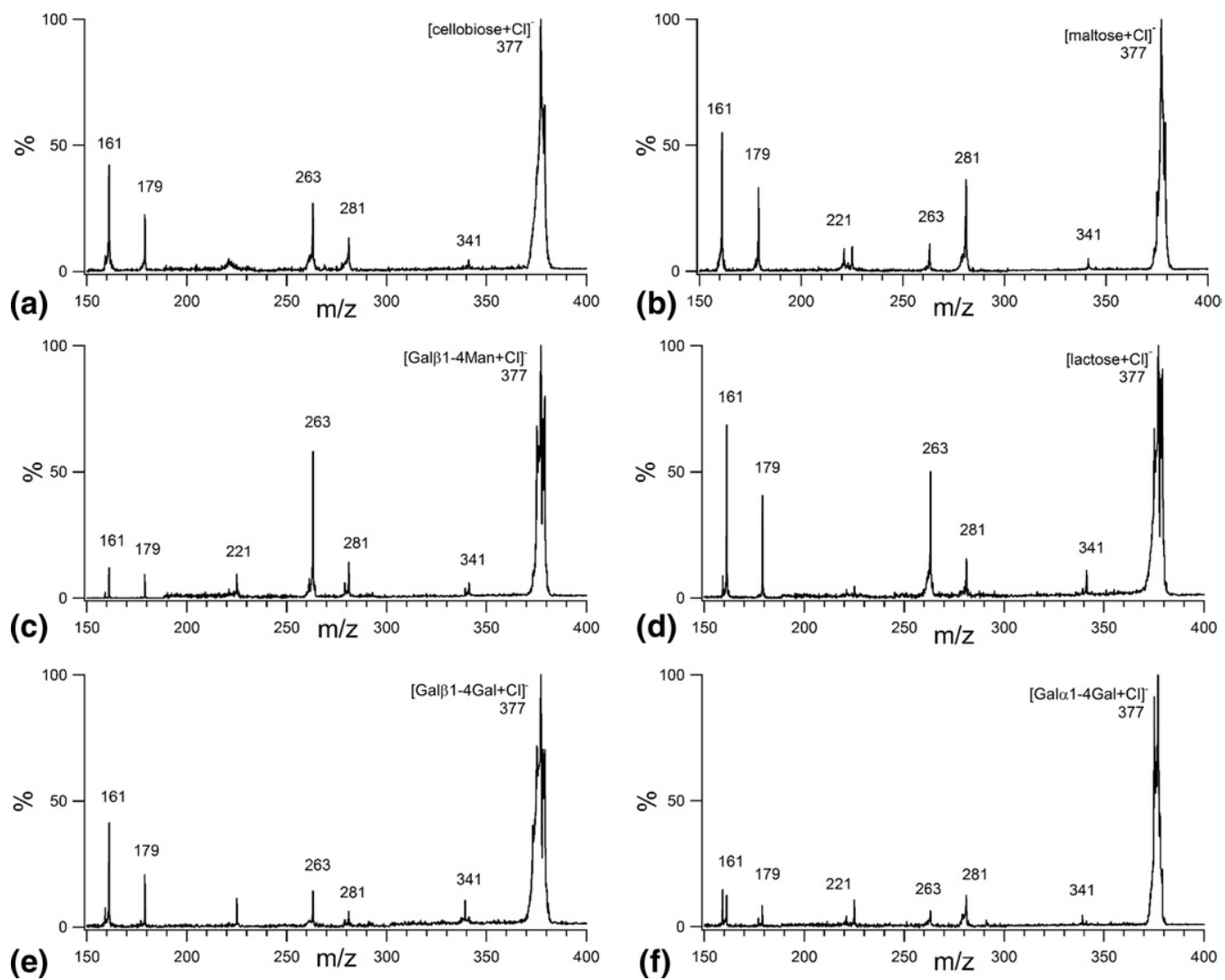

Figure 3. Negative ion PSD of chloride adducts of 1-4 linked disaccharides. (a) Cellobiose (Glc $\beta 1-4 \mathrm{Glc}$ ); (b) maltose (Glc $\alpha 1-4 \mathrm{Glc}$ ); (c) Gal $\beta 1-4 \mathrm{Man}$; (d) lactose (Gal $\beta 1-4 \mathrm{Glc})$; (e) Gal $\beta 1-4 \mathrm{Gal}$; and (f) Gal $\alpha 1-4 \mathrm{Gal}$. A clear-cut differentiation between the $\alpha$ - (maltose) and $\beta$-configuration (cellobiose) in 1-4 linked glucopyranosyl disaccharides can be made by simply checking whether the relative abundance ratio of $\mathrm{m} / \mathrm{z} 263: 281$ is larger than unity ( $\beta$ isomer) (Figure 3a) or smaller than unity ( $\alpha$ isomer) (Figure $3 b$ ). This peak intensity difference also holds true for other 1-4 linked disaccharides.

Table 2). Lastly, the 1-2 linked disaccharides (Figure 4e, $\mathrm{f}$, h; Table 2) are characterized by the appearance of PSD fragment peaks for $[\mathrm{M}-\mathrm{H}-162]^{-},[\mathrm{M}-\mathrm{H}-120]^{-}$, and $[\mathrm{M}-\mathrm{H}-78]^{-}$with the absence of the loss of $60 \mathrm{Da}$.

Observation of the $[\mathrm{M}-\mathrm{H}-162]^{-}$PSD fragment peak with a remarkably abundant $[\mathrm{M}-\mathrm{H}]^{-}$, appears to be characteristic of the 1-1 linked disaccharides (Figure $4 \mathrm{c})$. Although only one $1-1$ isomer (Glc $\alpha 1-1 \beta \mathrm{Glc}$ ) out of three possibilities (Glc $\alpha 1-1 \beta$ Glc, Glc $\alpha 1-1 \alpha$ Glc, and Glc $\beta 1-1 \beta$ Glc) has been studied here, we have included in Table 2 the fragmentation peaks that we tentatively assign as diagnostic for the 1-1 linked disaccharides since its fragmentation pattern is highly distinct (Figure $4 c$; Table 2). From decompositions of chloride adducts of Glc $\alpha 1-1 \beta \mathrm{Glc}$, a high intensity peak at $\mathrm{m} / \mathrm{z} 341$ corresponding to $[\mathrm{M}-\mathrm{H}]^{-}$is observed. Unlike other glucopyranosyl glucoses disaccharides where one of the glucoses is considered as the reducing ring, all three forms of trehalose are nonreducing disaccharides wherein the linkage has been formed between two reducing hydroxyl groups on the two glucose units. Apparently upon PSD, chloride adducts of trehalose require more energy to undergo initial $\mathrm{HCl}$ loss because they lack the acidic reducing end hydroxyl group. Thus, more of the available energy is consumed in the first step of decomposition ( $\mathrm{HCl}$ loss) and the remaining $[\mathrm{M}-\mathrm{H}]^{-}$product ions are less susceptible to consecutive decompositions [23]. This rationalizes the unusually high abundance of the $[\mathrm{M}-\mathrm{H}]^{-}$peak for trehalose that does not readily undergo further fragmentations.

Deprotonated molecules $[\mathrm{M}-\mathrm{H}]^{-}$at $\mathrm{m} / \mathrm{z} 341$ and the peak at $m / z 179$, corresponding to the loss of a hexose from $[\mathrm{M}-\mathrm{H}]^{-}$, are consistently observed in PSD studies of [disaccharide $+\mathrm{Cl}^{-}$adducts for all hexose-hexose disaccharides, although the intensities vary substantially. This observation of peaks at $\mathrm{m} / \mathrm{z} 179$ in PSD studies of [disaccharide $+\mathrm{Cl}^{-}$for all hexosehexose disaccharides shows great similarity to the decomposition patterns of [disaccharide $-\mathrm{H}]^{-}$ions reported in LSIMS [18], FAB-MS/MS [17] and an ESI MS/MS study of [disaccharide $+\mathrm{Cl}]^{-}$[23], but differs somewhat from a previous FAB-MS/MS study of [disaccharide $-\mathrm{H}]^{-}$[16]. Similarities in the decomposition spectra of [disaccharide $+\mathrm{Cl}^{-}$and [disaccharide $\left.-\mathrm{H}\right]^{-}$ precursors strongly suggest that the fragmentation pathway of the former involves initial neutral loss of $\mathrm{HCl}$ from the chloride adducts before consecutive decompositions.

The neutral losses for differentiating linkage positions reported above in our MALDI-PSD of [saccharide $+\mathrm{Cl}]^{-}$ 

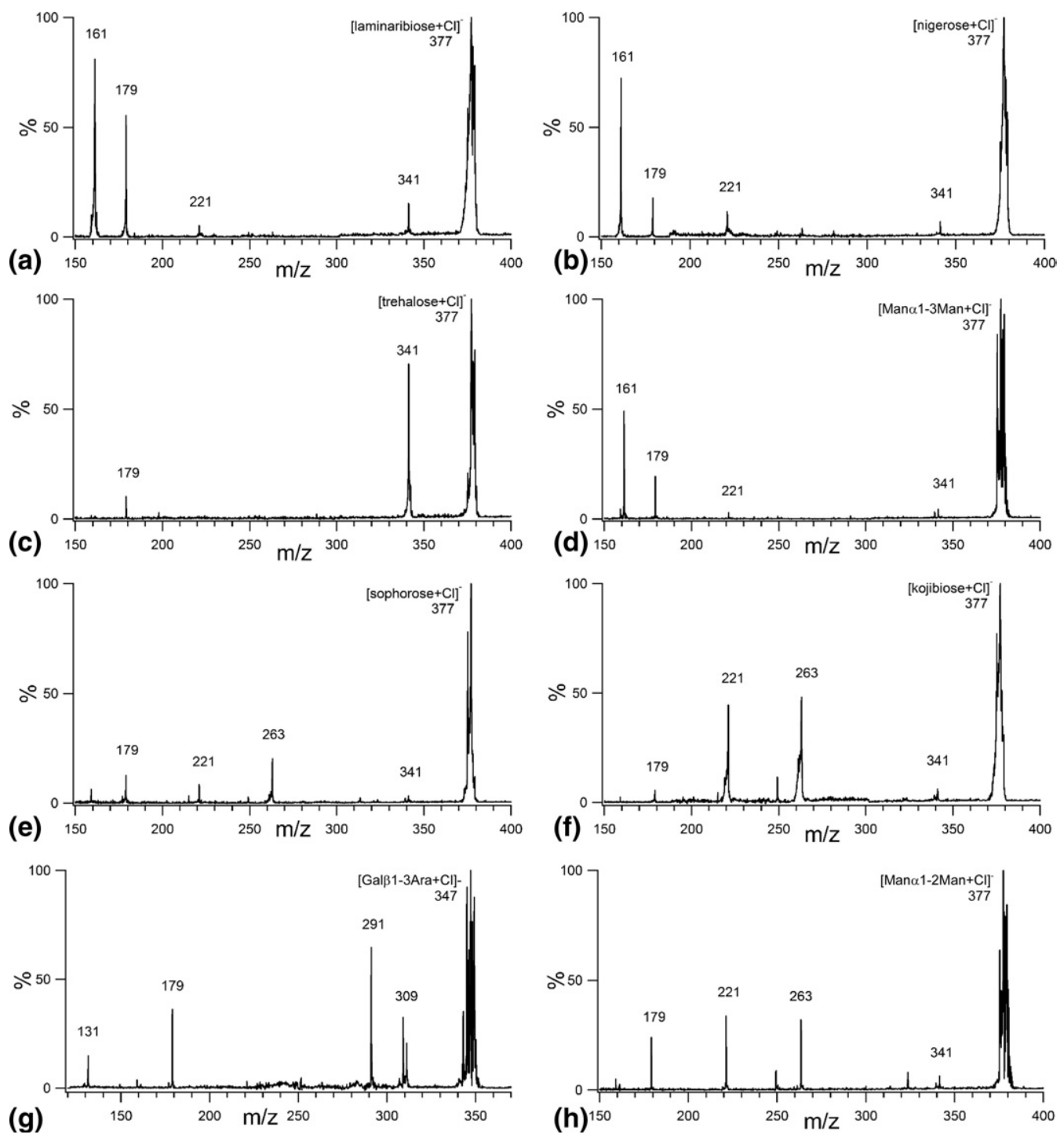

Figure 4. Negative ion PSD of chloride adducts of (a) laminaribiose (Glc $\beta 1-3 \mathrm{Glc}$ ); (b) nigerose (Glc $\alpha 1-3 \mathrm{Glc}) ;$ (c) trehalose (Glc $\alpha 1-1 \beta \mathrm{Glc}) ;(\mathbf{d})$ Man $\alpha 1-3 \mathrm{Man} ;(\mathbf{e})$ sophorose (Glc $\beta 1-2 \mathrm{Glc}$ ); (f) kojibiose (Glc $\alpha 1-2 \mathrm{Glc})$; (g) Gal $\beta 1-3 \mathrm{Ara}$; and (h) Man $\alpha 1-2 \mathrm{Man}$. For 1-3 glycosyl linkages, the relative abundance ratio of $m / z$ 161:179 is consistently higher for the $\alpha$ isomers (b), (d) than for the $\beta$ isomer (a). The difference in relative ratios is sufficiently large to permit distinction between the $\alpha$ - and $\beta$-configurations. For $1-2$ glycosyl linkages, the relative abundance ratio of $\mathrm{m} / \mathrm{z}$ 263:221 is consistently lower for the $\alpha$ isomers (f), (h) than for the $\beta$ isomer (e), which allows for clear differentiation. For 1-1 linked trehalose (c), a nonreducing disaccharide, unusually high peak intensity at $m / z 341$, is observed because of the lack of reducing end hydroxyl group. For Gal $\beta 1-3 \mathrm{Ara}(\mathrm{g})$, a hexose-pentose, prominent product ion peaks at $\mathrm{m} / \mathrm{z} 179$ (with charge retention on the nonreducing ring) and at $\mathrm{m} / \mathrm{z} 131$ (with charge retention on the reducing ring) are produced upon unambiguous cleavage of the glycosidic bond on the reducing end side.

precursors are similar, but not identical, to those from other studies [13, 16-18, 23, 36]. These similarities in neutral losses are observed even under largely variable conditions (e.g., positive mode versus negative mode; lithiated cations versus deprotonated molecules versus chloride adducts of saccharides; sector high-energy CAD versus low-energy CAD versus PSD; LSIMS versus FAB versus ES versus MALDI). This uniformity in behavior suggests a correlation between the linkage positions and fragmentation mechanisms including steric requirements for cross-ring cleavages (comprehending hydrogen transfers). The minor differences between our results and those obtained by Yamagaki et al. [36] are likely to be caused by a combination of two different effects. First, the smaller size oligosaccharides employed in our study should have a higher propensity to fragment than the larger varieties used in theirs (the larger the number of monomers, the more degrees of freedom (vibrational modes) exist [54]). Secondly, the laser intensity in our PSD experiments 
Table 2. Diagnostic PSD neutral losses and fragment peaks (in parentheses) of chloride adducts of glucopyranosyl glucoses as well as other hexose:hexose disaccharides. Mass differences resulting from neutral losses are calculated from deprotonated saccharides. A set of empirical criteria concerning the RPIs of selected characteristic peak pairs are also developed as a reliable means of differentiation of anomeric configurations (last column on right); all other data apply to either anomeric configuration

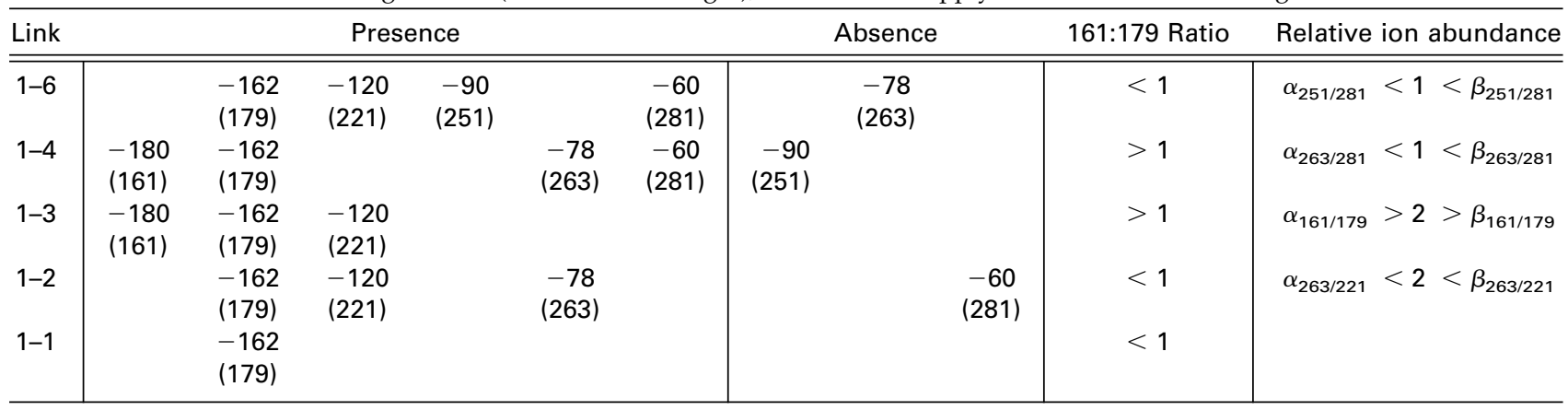

using the linear-field reflectron can be changed greatly from segment to segment, to improve fragment ion abundances without saturating the detector. It is an advantage compared to PSD with a curved-field reflectron where the chosen laser intensity may create a dynamic range problem whereby lower intensity fragment ion signals are barely visible next to high intensity peaks.

Differentiation of anomeric configurations is achieved after knowing the linkage position because PSD mass spectra of the chloride adducts of the disaccharides with the same linkage but different anomeric configurations exhibit clear differences in the relative abundances of selected diagnostic peak pairs, independent of the constituent pyranose. A set of empirical criteria concerning the relative peak intensities of the selected characteristic peak pairs has been developed and is summarized in Table 2 .

The $\alpha$ - and $\beta$-configuration in the 1-6 linked disaccharides (Table 2) can be readily differentiated by examining whether the relative abundance ratio of $\mathrm{m} / \mathrm{z}$ 251:281 is larger than unity ( $\beta$ isomer) (Figure $2 \mathrm{a}, \mathrm{c}$ ) or smaller than unity ( $\alpha$ isomer) (Figure $2 b, d, e)$. Similarly, a clear-cut differentiation between the $\alpha$ - and $\beta$-configuration in the 1-4 linked disaccharides (Table 2) can be made by simply checking whether the relative abundance ratio of $m / z$ 263:281 is larger than unity ( $\beta$ isomer) (Figure 3a, $\mathrm{c}-\mathrm{e}$ ) or smaller than unity ( $\alpha$ isomer) (Figure $3 b, f)$. For 1-3 glycosyl linkages, the relative abundance ratio of $m / z 161: 179$ is consistently larger for the $\alpha$ isomers (larger than 2) (Figure $4 b, d$ ) than for the $\beta$ isomer (smaller than 2) (Figure 4a) (Table 2). The empirical dividing line (2 in this case) provides a reliable means of differentiation. Likewise, the relative abundance ratio of $\mathrm{m} / \mathrm{z} 263: 221$ is invariably lower for the $\alpha$ isomers (smaller than 2) (Figure 4f, h) than for the $\beta$ isomer (larger than 2) (Figure $4 \mathrm{e}$ ) in the 1-2 linked disaccharides (Table 2).

Notably, the relative abundance of $m / z 161$ versus $m / z 179$ in the negative ion PSD mass spectra of [disaccharide $+\mathrm{Cl}^{-}$varies largely for the different linkages. The 1-6, 1-2, and 1-1 linked disaccharides show higher abundances of $m / z 179$ versus $m / z 161$, while the reverse is observed for 1-4 and 1-3 linked disaccharides, which is similar to previous studies in LSIMS/FTMS [18] and ES MS/MS [23]. This distinction appears to be a potential indicator to differentiate the 1-6, 1-2, and 1-1 linkages (higher $m / z$ 179) from the 1-4 and 1-3 linkages (higher $m / z$ 161).

\section{Determination of the Reducing End}

All of the disaccharides studied herein so far are hexose-hexose and the different stereoisomeric configurations cannot be discriminated by single-stage MS. However, sequence information can be obtained by MS when the constituent monosaccharide units have different masses. For example, a hexose-pentose disaccharide: Gal $\beta 1$-3Ara (23), has two monosaccharide units with different masses. The PSD mass spectrum of the chloride adduct of Gal $\beta 1-3$ Ara at $m / z 347$ is shown in Figure $4 \mathrm{~g}$. Along with the deprotonated molecule [M $\mathrm{H}^{-}$, prominent product ion peaks at $\mathrm{m} / \mathrm{z} 179$ (with charge retention on the nonreducing ring) and at $m / z$ 131 (with charge retention on the reducing ring) are produced upon unambiguous cleavage of the glycosidic bond on the reducing end side. Cleavages on the nonreducing side forming product ions at $\mathrm{m} / \mathrm{z} 161$ or $m / z 149$ are disfavored [18] and are detected in much lower abundances. A very low intensity peak at $m / z 221$ is also observed. This fragmentation pattern is very similar to the 1-3 linked hexose-hexose disaccharides (Table 2).

\section{Influence of Laser Intensity on Relative Peak Intensities of Diagnostic PSD Fragment Pairs}

Relative peak intensities (RPIs) are not generally reliably reproducible in PSD when these spectra are composites of several different "stitched" spectral segments acquired under somewhat varying ionization conditions [27]. However, employing a novel approach with our MALDI linear-field reflectron TOF mass spectrometer, we demonstrated [53] that even if target crystals vary substantially in shape and quality, rather repro- 
ducible relative PSD peak intensities can be acquired within the same PSD segment of a limited $\mathrm{m} / \mathrm{z}$ range $(\sim 40 \mathrm{~m} / \mathrm{z})$. This possibility will prove to be convenient for laboratories that do not have a curved-field reflectron [36-38, 55] MALDI-TOF mass spectrometer that allows acquisition of an entire PSD spectrum under the same conditions for each laser shot.

While our initial studies [53] of glucopyranosyl glucose, positional isomeric pairs, and anomeric pairs were performed using a uniform laser intensity, it is impractical to acquire all PSD spectra using the same laser intensity. Thus, a study was undertaken to see whether the relative peak intensities of our proposed diagnostic fragment pairs vary greatly with laser intensity. The 1-6 and 1-4 linked glucopyranosyl glucose disaccharides were selected for this study. The stability of the relative ion abundances was checked for four disaccharides with the laser intensity value set at increasing increments (nine total for each disaccharide) up to about 1.5 times the threshold value (Figure 1e, f). Using four repeat measurements at each point, the RPI of each diagnostic peak pair was calculated with the peak intensity of $\mathrm{m} / \mathrm{z} 281$ normalized to $100 \%$. As can be seen from Figure 1e and $f$, the relative peak intensities are fairly stable regardless of the laser intensity used. Considering the poorly controllable variations in crystallization on the MALDI target, the reproducibility is satisfactorily high and the anomeric configurations can be unambiguously distinguished (no overlap in error bars).

\section{PSD of Chloride Adducts of Fructose-Containing Disaccharides}

Figure 5 shows the PSD mass spectra of $[\mathrm{M}+\mathrm{Cl}]^{-}$ of fructose-containing saccharides. It is obvious that fructose-containing disaccharide isomers (19-22) with differing linkage positions give quite different PSD product ion spectra (Figure $5 \mathrm{a}-\mathrm{d}$ ). For the fructose-containing disaccharide series, observation of PSD peaks at $\mathrm{m} / \mathrm{z}$ $179,221,251,281$, and 341 is characteristic of the $1-6$ linkage (Figure 5a); appearance of PSD peaks at $m / z 161$, 179 , and 251 is indicative of the 1-3 linkage (Figure $5 c$ ); and PSD peaks appearing at $m / z 179,197,215$, and 341 is characteristic of the 1-2 linkage (Figure $5 \mathrm{~d}$ ). Cross-
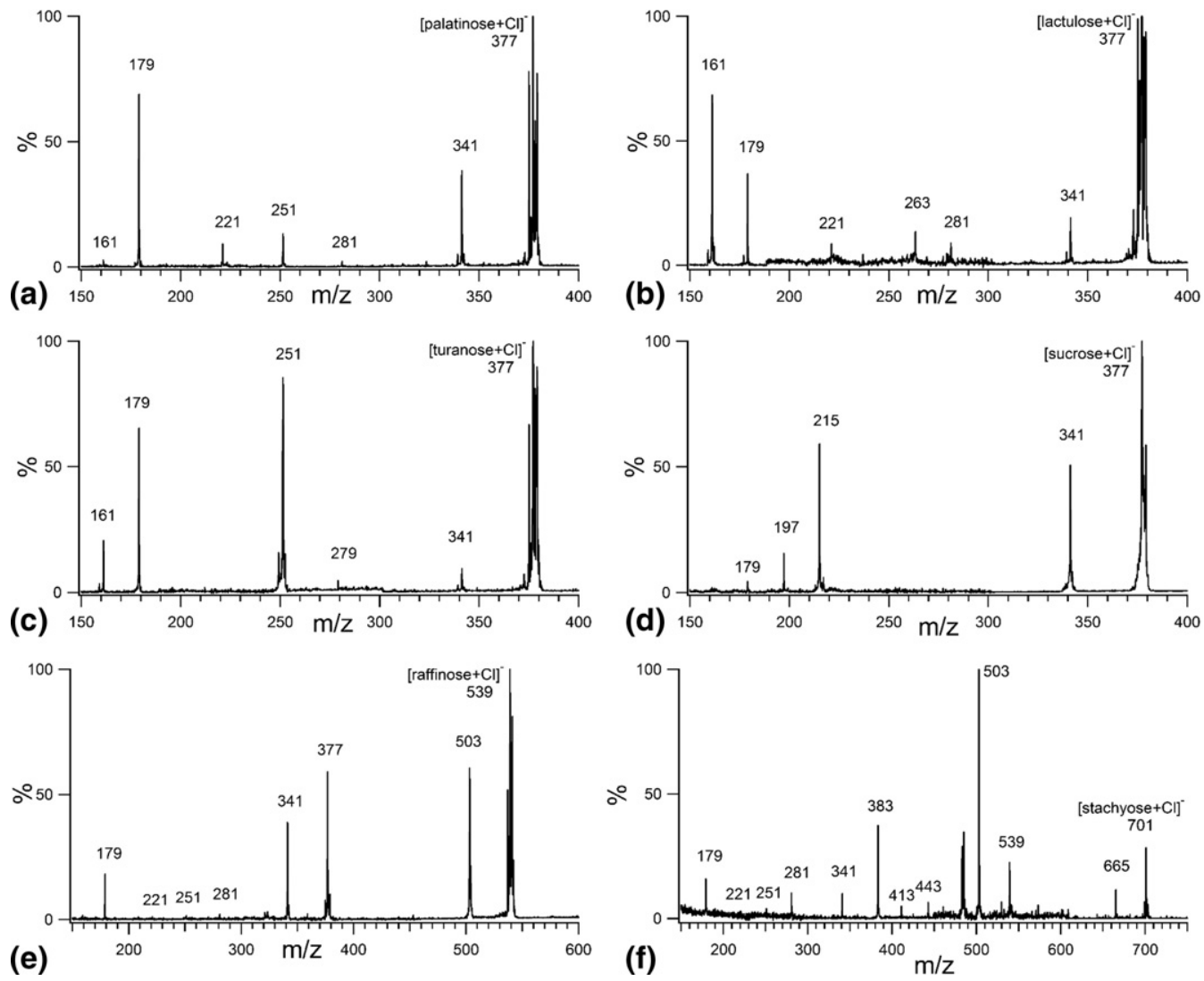

Figure 5. Negative ion PSD of chloride adducts of fructose-containing saccharides. (a) Palatinose (Glc $\alpha 1-6 \mathrm{Fru})$; (b) lactulose (Gal $\beta 1-4 \mathrm{Fru})$; (c) turanose (Glc $\alpha 1-3 \mathrm{Fru})$; (d) sucrose (Glc $\alpha 1-2 \mathrm{Fru})$; (e) raffinose (Gal $\alpha 1-6 \mathrm{Glc} \alpha 1-2 \mathrm{Fru}$ ); and (f) stachyose (Gal $\alpha 1-6 \mathrm{Gal} \alpha 1-6 \mathrm{Gl} c \alpha 1-2 \mathrm{Fru}$ ). PSD of the chloride adduct of nonreducing sucrose (d) yields chlorine-containing fragment ions ( $\mathrm{m} / \mathrm{z} 215$ and $\mathrm{m} / \mathrm{z} 197)$. Chlorine-containing product ions are also observed at $\mathrm{m} / \mathrm{z} 377$ for raffinose (e) and at $\mathrm{m} / \mathrm{z} 539$ for stachyose (f) due to the neutral loss of the fructose residue (162 Da neutral) from the corresponding $[\mathrm{M}+\mathrm{Cl}]^{-}$precursors. 
ring cleavages are not prominent for Gal $\beta 1-4$ Fru and observation of PSD peaks at $m / z 161$ and 179, with small cross-ring cleavage peaks at $m / z 263$ and 281, are characteristic of the 1-4 linkage (Figure 5b). The PSD spectra presented here are qualitatively similar to those obtained by ES-CID of chloride adducts of these fructose-containing disaccharides [23], except for Gal $\beta 1-4 \mathrm{Fru}$, where the cross-ring cleavages of fructose were not observed under ES-CID [23]. On the other hand, our PSD spectrum of chloride adducts of Gal $\beta 1$ 4Fru is very similar to that of $[\mathrm{M}-\mathrm{H}]^{-}$obtained under FAB-CID [17]. Also, the MALDI-PSD fragmentation patterns of 1-6 and 1-4 linked fructose-containing disaccharides were similar to their counterparts obtained from non fructose-containing disaccharides.

Sucrose (Glc $\alpha 1-2 F r u$ ) (Figure $5 \mathrm{~d}$ ) is unique among all the disaccharides studied here. First, it is a fructosecontaining disaccharide. Second, it is a nonreducing disaccharide wherein the linkage is formed between two reducing hydroxyl groups on the glucose and the fructose units. The deprotonated 1-2 linked molecule $[\mathrm{M}-\mathrm{H}]^{-}$at $m / z 341$ appears in substantially higher abundance than those with 1-3, 1-4, and 1-6 linkages. An interesting phenomenon is that the PSD spectrum of chloride adducts of sucrose also shows chloridecontaining product ions at $m / z 197$ and 215 (Figure 5d). The observation of chlorine-containing fragments from chloride adduct precursors has not yet been reported in MALDI-PSD MS. The unusually high abundance of [M $-\mathrm{H}]^{-}$peaks at $m / z 341$ may be attributed to the lower acidity of the nonreducing end sugar, causing more energy to be consumed during the neutral loss of $\mathrm{HCl}$ from $[\mathrm{M}+\mathrm{Cl}]^{-}$, leaving the formed $[\mathrm{M}-\mathrm{H}]^{-}$ion with less internal energy for further decomposition [23].

\section{Linkage and Anomeric Configuration Analysis of Larger Oligosaccharide Adducts by PSD}

The empirical "rules" listed in Table 2, which were initially constructed from the PSD spectra of chloride adducts of glucopyranosyl glucose disaccharides and have shown suitability for other disaccharides, will now be tested on larger size oligosaccharides to assess the general applicability of this characterization method. Both raffinose (Gal $\alpha 1-6 \mathrm{Glc} \alpha 1-2 \mathrm{Fru}$ ) (Figure 5e) and stachyose (Gal $\alpha 1-6 \mathrm{Gal} \alpha 1-6 \mathrm{Glc} \alpha 1-2 \mathrm{Fru}$ ) (Figure 5f) are nonreducing saccharides that each contains a Glc $\alpha 1-$ 2Fru moiety at what is normally the reducing end. PSD of chloride adducts of Glc $\alpha 1-2$ Fru yielded unusual chlorine-containing product ions (Figure 5d) and chlorine-containing product ions are also observed at $\mathrm{m} / \mathrm{z} 377$ for raffinose (Figure 5e) and at $\mathrm{m} / \mathrm{z} 539$ for stachyose (Figure $5 \mathrm{f}$ ) due to the neutral loss of the fructose residue (162 Da neutral) from the corresponding $[\mathrm{M}+\mathrm{Cl}]^{-}$precursors. But no PSD peaks at $m / z 197$ are observed in either case, which contrasts with the previous ES-CID study [23]. The observation of chlorine-containing product ions corresponding to loss of fructose as a result of cleavage on the fructose side of the glycosidic bond upon PSD of $[\mathrm{M}+\mathrm{Cl}]^{-}$(e.g., $\mathrm{m} / z 215$ from sucrose (Figure 5d), $m / z 377$ from raffinose (Figure $5 e$ ), and $m / z 539$ from stachyose (Figure 5f)), has been found to be diagnostic for the Glc $\alpha 1-2$ Fru linkage at the downstream end [23]. We are therefore quite confident that each of these three chlorine-containing ions arises from cleavage of the last glycosidic bond at the downstream end. This evidence supports the notion that stepwise fragmentation of oligosaccharides originates at the downstream end [16]. In sharp contrast, chlorinecontaining fragments are not observed in PSD of the 1-1 linked pyranose on the reducing end (Figure 4f). PSD of chloride adducts clearly serves as a means to differentiate a fructose on the reducing end from a 1-1 linked pyranose at the same position, which are practically indistinguishable by fragmentation under lowenergy CID [19].

As shown in Figure 5e, the 1-6 linkage between the two upstream sugar rings in raffinose can be clearly deduced (Table 2) by the major losses of $60 \mathrm{Da}(\mathrm{m} / z 281)$, $90 \mathrm{Da}(m / z$ 251), $120 \mathrm{Da}(m / z 221)$, and $162 \mathrm{Da}(m / z$ 179) from the negatively charged disaccharide moiety at $m / z$ 341 , together with the absence of a peak corresponding to loss of $78 \mathrm{Da}$. The $\alpha$-configuration of this 1-6 linkage can be safely assigned since the RPI of $m / z 251: 281$ is smaller than unity (Table 2). In combination with the observation of the chlorine-containing ion at $\mathrm{m} / \mathrm{z} 377$ that is diagnostic of Glc $\alpha 1-2$ Fru at the downstream end, the appearance of peaks corresponding to consecutive cleavages at points progressively further upstream serves as strong support for a stepwise cleavage process, going from the downstream (reducing) end to the upstream (nonreducing) end [16].

For stachyose (Figure 5f), the major losses of $60 \mathrm{Da}$ $(m / z 281), 90 \mathrm{Da}(m / z 251), 120 \mathrm{Da}(\mathrm{m} / z 221)$, and $162 \mathrm{Da}$ $(m / z$ 179) from the negatively charged disaccharide moiety at $m / z 341$, together with the absence of a peak corresponding to loss of $78 \mathrm{Da}$, indicate the 1-6 linkage between the first and second sugar ring. The major losses of $60 \mathrm{Da}(\mathrm{m} / \mathrm{z} 443), 90 \mathrm{Da}(\mathrm{m} / \mathrm{z} 413), 120 \mathrm{Da}(\mathrm{m} / \mathrm{z} 383)$, and $162 \mathrm{Da}(\mathrm{m} / z$ 341) from the negatively charged trisaccharide moiety at $m / z 503$, indicate another 1-6 linkage between rings 2 and 3 . The $\alpha$-configuration of these two 1-6 linkages in stachyose can be safely assigned since the RPI of both $m / z$ 251:281 and $m / z$ 413:443 (analogous cross-ring cleavage, with one added monosaccharide) are smaller than unity (Table 2). Again, stepwise cleavage of glycosidic linkages, going from the downstream end (yielding initially the chlorine-containing ion at $\mathrm{m} / \mathrm{z} 539$ diagnostic of Glc $\alpha 1-2 F r u$ ) to the upstream end [16], is supported by the obtained spectrum.

The negative ion MALDI-PSD mass spectrum of the chloride adduct of isomaltotriose (Glc $\alpha 1-6 \mathrm{Glc} \alpha 1-6 \mathrm{Glc}$ ) (26) is shown in Figure 6a, which is essentially the same as that of the three upstream monosaccharides contained in tetrameric stachyose (Figure 5f). Both the two 1-6 linkages and the two associated $\alpha$-configurations can be deduced by a similar exercise. 

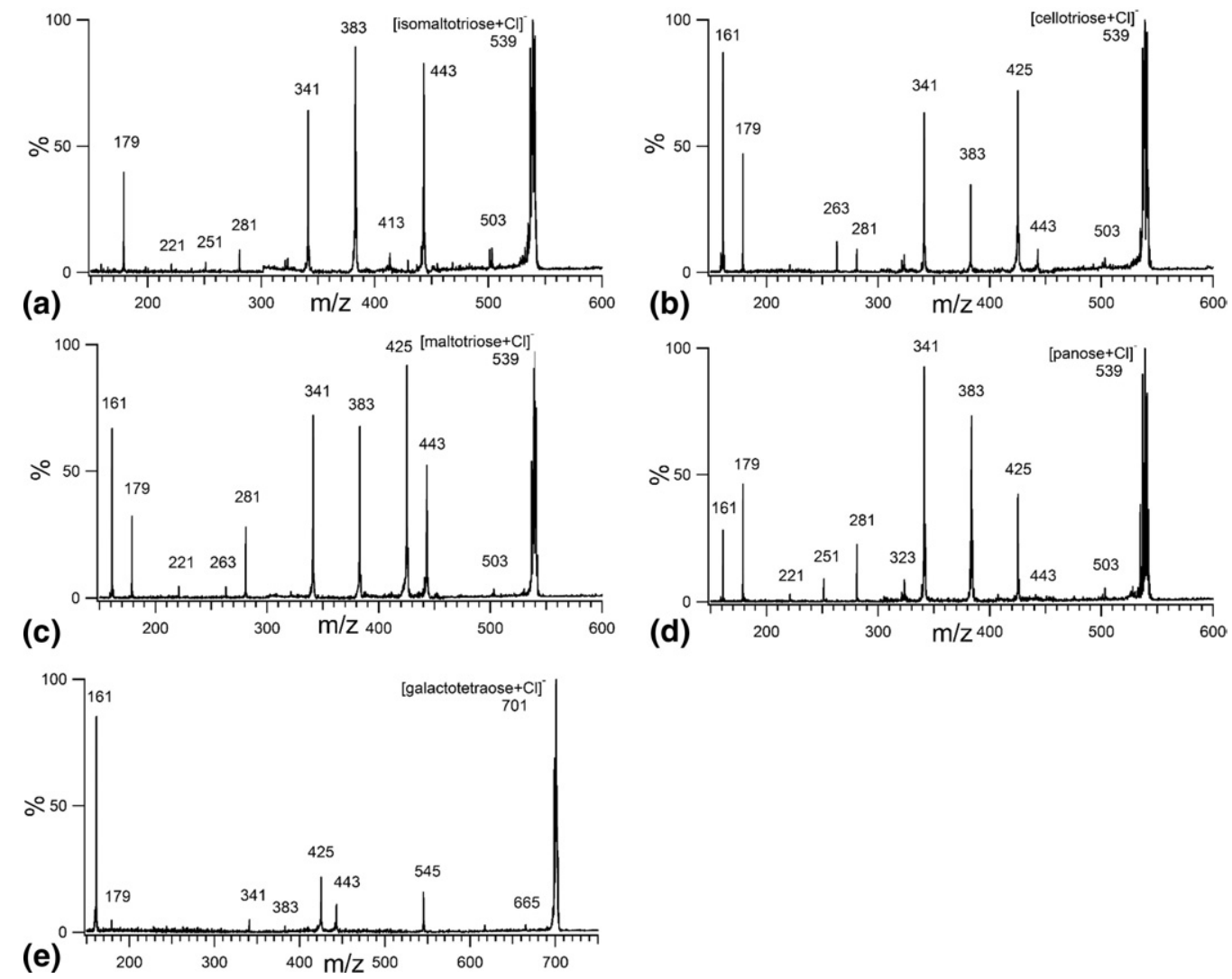

Figure 6. Negative ion PSD of chloride adducts of oligosaccharides. (a) Isomaltotriose (Glc $\alpha 1$ 6Glc $\alpha 1-6 \mathrm{Glc}$ ); (b) cellotriose (Glc $\beta 1-4 \mathrm{Glc} \beta 1-4 \mathrm{Glc}$ ); (c) maltotriose (Glc $\alpha 1-4 \mathrm{Glc} \alpha 1-4 \mathrm{Glc}$ ); (d) panose

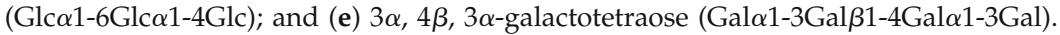

The negative ion MALDI-PSD mass spectra of the chloride adducts of cellotriose (Glc $\beta 1-4 \mathrm{Glc} \beta 1-4 \mathrm{Glc})$ (27) (Figure 6b) and maltotriose (Glc $\alpha 1-4 \mathrm{Gl} c \alpha 1-4 \mathrm{Glc})$ (28) (Figure $6 c)$ are similar. In each case, the two 1-4 linkages on each sugar can be verified due to appearance of the diagnostic fragments given in Table 2 . The $\beta$-configurations of the two 1-4 linkages in cellotriose can be safely assigned since the RPI of both $\mathrm{m} / \mathrm{z} 263: 281$ and $\mathrm{m} / \mathrm{z}$ 425:443 (analogous cross-ring cleavage, one added monosaccharide) are larger than unity (Table 2). For maltotriose, the $\alpha$-configuration between the first and second ring (nonreducing end) can be safely assigned since the RPI of $\mathrm{m} / \mathrm{z}$ 263:281 is smaller than unity (Table 2). However, the RPI of $m / z 425$ versus $m / z 443$ is larger than unity, which according to the proposed criteria implies $\beta$-configuration with 1-4 linkage and fails to show the correct $\alpha$-configuration of the reducing end 1-4 linkage in maltotriose.

The negative ion MALDI-PSD mass spectrum of the chloride adduct of panose (Glc $\alpha 1-6 \mathrm{Glc} \alpha 1-4 \mathrm{Glc}$ ) (29) is reported in Figure 6d. The 1-4 linkage of the reducing end and the 1-6 linkage type between the first and second ring (nonreducing end) in panose can both be clearly obtained by examining the major neutral losses (Table 2). The $\alpha$-configuration of the 1-6 linkage can be safely assigned since the RPI of $\mathrm{m} / \mathrm{z} 251: 281$ is smaller than unity (Table 2). The RPI of $m / z 425$ versus $m / z 443$ in panose, however, fails to show characteristics of the $\alpha$-configuration with a 1-4 linkage. Once again, the evidence supports a stepwise cleavage of glycosidic linkages, starting from the downstream (or reducing) end [16].

The negative ion MALDI-PSD mass spectrum of the chloride adduct of $3 \alpha, 4 \beta, 3 \alpha$-galactotetraose (Gal $\alpha 1$ $3 \mathrm{Gal} \beta 1-4 \mathrm{Gal} \alpha 1-3 \mathrm{Gal}$ ) (30) appears in Figure 6e. The identity of the 1-3 linkage of the reducing end in galactotetraose is only supported by one major loss of $120 \mathrm{Da}(\mathrm{m} / \mathrm{z} 545)$ from the $[\mathrm{M}-\mathrm{H}]^{-}$ion at $\mathrm{m} / \mathrm{z} 665$. In PSD of chloride adducts of 1-3 linked disaccharides (laminaribiose and nigerose), only one cross-ring fragment via loss of 120 is observed (Figure $4 a$ and $b$ ). The 1-4 linkage between the second and third ring, and the 1-3 linkage between the first and second ring (nonreducing end) in galactotetraose can both be deduced from consideration of the neutral losses (Table 2). The $\alpha$-configuration between the first and second ring (nonreducing end) can be determined by the RPI of $m / z 161$ versus $m / z 179$, which is larger than 2 (Table 2). The larger than unity RPI of $\mathrm{m} / \mathrm{z}$ 425:443 (analogous to 263:281 in Table 2, one added monosaccharide) clearly reveals the $\beta$-configuration between rings 2 and 3 in galactotetraose, while the anomeric configuration of the 1-3 linkage of the reducing end in galactotetraose 
cannot be determined because of the lack of pertinent fragmentations.

\section{Conclusions}

Various anions can form anionic adducts with oligosaccharides in negative ion MALDI-MS. Employing negative ion MALDI in the presence of various anions, weakly acidic and neutral oligosaccharides can form $[\mathrm{M}+\text { anion }]^{-}$adducts in varying degrees of preference to $[\mathrm{M}-\mathrm{H}]^{-}$. The anion attachment approach provides a simple means to simultaneously analyze neutral and acidic carbohydrates without switching the instrument polarity.

Contrary to common opinion that relative peak intensities are not generally reliable in linear reflectron PSD, we demonstrate that the relative peak intensities of the oligosaccharide fragment peaks intentionally acquired within the same PSD segment are rather stable, even if the laser intensities vary greatly and the target crystals are not uniform with respect to shape and quality. Our proposed characteristic neutral losses in MALDI-PSD mass spectra of the chloride adducts of neutral oligosaccharides and the relative ion abundances of selected diagnostic fragment pairs allow simultaneous determination of both linkage information and anomeric configurations of the oligosaccharides.

Competitive fragmentation pathways are revealed and rationalized in PSD processes of chloride adducts of oligosaccharides. For specific glycosidic linkage types, PSD spectra of oligosaccharides with the same anomeric configuration show the same trend of relative ion abundances for specified diagnostic fragment peaks, independent of monosaccharide structure. This strongly indicates that the fragmentation pathways observed in negative ion PSD spectra are largely affected by the anomeric configuration between the monosaccharide rings for the particular linkage positions while downplaying the importance of the specific types of monosaccharide present in the reducing or nonreducing position. It thus has become clear that differentiating anomeric configuration of glycosidic bonds is viable by comparing relative peak intensities of diagnostic peaks in negative ion PSD via anion attachment. The fragmentation profiles and relative peak abundances in PSD spectra are expected to present important hints to determining the glycosidic linkage types and anomeric configurations of more complex glycoconjugates. The empirical rules listed in Table 2 hold without exception for all the tested disaccharides (18 in total). When larger oligosaccharides are tested by these same rules, most cases conform; however, in two instances, the $\alpha$-configuration of 1-4 linkages was incorrectly assessed. The additional monosaccharides present in the larger oligosaccharides must therefore influence the preferred decomposition pathways in these two cases. In moving from disaccharides to larger oligosaccharides, the rates of the two competitive processes leading to a given pair of diagnostic ions may be altered by more severe steric constraints, or the increased number of decomposition channels, or a diminution of internal energy in specific vibrational modes and the related increase in kinetic shift.

The potential usage of MALDI linear reflectron TOF MS in stereoisomer determination has thus been greatly expanded. Considering the popularity of conventional MALDI-TOF MS world-wide and the fact that it will remain a major workhorse for the near future, our results will hopefully inspire more interest in PSD analysis of glycoconjugates.

\section{Acknowledgments}

The authors acknowledge support for this work by the National Science Foundation grants CHE-0518288, DBI- 0619272 and by the Louisiana Board of Regents through HEF (2001-06)-08.

\section{References}

1. Bertozzi, C. R.; Kiessling, L. L. Chemical Glycobiology. Science 2001, 291(5512), 2357-2364.

2. Dwek, R. A., Edge, C. J., Harvey, D. J., Wormald, M. R., Parekh, R. B. Analysis of Glycoprotein-Associated Oligosaccharides. Ann. Rev Biochem. 1993, 62, 65-100.

3. Schulten, H. R. Biochemical, Medical, and Environmental Applications of Field-Ionization and Field-Desorption Mass Spectrometry. Int. J. Mass Spectrom. Ion Processes 1979, 32(2/3), 97-283.

4. Cerny, R. L.; Tomer, K. B.; Gross, M. L. Desorption Ionization Combined with Tandem Mass Spectrometry-Advantages for Investigating Complex Lipids, Disaccharides, and Organometallic Complexes. Org. Mass Spectrom. 1986, 21(10), 655-660.

5. Coates, M. L.; Wilkins, C. L. Laser Desorption Fourier Transform Mass Spectra of Malto-Oligosaccharides. Biomed. Mass Spectrom. 1985, 12(8), $424-428$.

6. Lam, Z.; Comisarow, M. B.; Dutton, G. G. S. Structural and Reaction Assignments for Some Common Polysaccharides Using Laser Desorption Ionization Fourier Transform Ion Cyclotron Resonance Spectroscopy. Anal. Chem. 1988, 60(20), 2304-2306.

7. Domon, B.; Costello, C. E. Structure Elucidation of Glycosphingolipids and Gangliosides Using High-Performance Tandem Mass Spectrometry. Biochemistry 1988, 27(5), 1534-1543.

8. Dell, A.; Taylor, G. W. High-Field Magnet Mass Spectrometry of Biological Molecules. Mass Spectrom. Rev. 1984, 3(3), 357-394.

9. Dell, A. Preparation and Desorption Mass Spectrometry of Permethyl and Peracetyl Derivatives of Oligosaccharides. Methods Enzymol. 1990, 193, 647-660.

10. Dallinga, J. W.; Heerma, W. Positive Ion Fast Atom Bombardment Mass Spectrometry of Some Small Oligosaccharides. Biol. Mass Spectrom. 1991, 20(3), 99-108.

11. Teesch, L. M.; Adams, J. Metal Ions as Special Reagents in Analytical Mass Spectrometry. Org. Mass Spectrom. 1992, 27(9), 931-943.

12. Zhou, Z. R.; Ogden, S.; Leary, J. A. Linkage Position Determination in Oligosaccharides MS/MS Study of Lithium-Cationized Carbohydrates. J. Org. Chem. 1990, 55(20), 5444-5446.

13. Hofmeister, G. E.; Zhou, Z.; Leary, J. A. Linkage Position Determination in Lithium-Cationized Disaccharides-Tandem Mass-Spectrometry and Semiempirical Calculations. J. Am. Chem. Soc. 1991, 113(16), 5964-5970.

14. Staempfli, A.; Zhou, Z. R.; Leary, J. A. Gas-Phase Dissociation Mechanisms of Dilithiated Disaccharides Tandem Mass Spectrometry and Semiempirical Calculations. J. Org. Chem. 1992, 57(13), 3590-3594.

15. Smith, G.; Leary, J. A. Differentiation of Stereochemistry of Glycosidic Bond Configuration: Tandem Mass Spectrometry of Diastereomeric Cobalt-Glucosyl-Glucose Disaccharide Complexes. J. Am. Soc. Mass Spectrom. 1996, 7(9), 953-957.

16. Garozzo, D.; Giuffrida, M.; Impallomeni, G.; Ballistreri, A.; Montaudo, G. Determination of Linkage Position and Identification of the Reducing End in Linear Oligosaccharides by Negative Ion Fast Atom Bombardment Mass Spectrometry. Ana. Chem. 1990, 62(3), 279-286.

17. Dallinga, J. W.; Heerma, W. Reaction-Mechanism and Fragment Ion Structure Determination of Deprotonated Small Oligosaccharides, Studied by Negative Ion Fast-Atom-Bombardment (Tandem) Mass Spectrometry. Biol. Mass Spectrom. 1991, 20(4), 215-231.

18. Carroll, J. A.; Ngoka, L.; Beggs, C. G.; Lebrilla, C. B. Liquid SecondaryIon Mass Spectrometry Fourier-Transform Mas -Spectrometry of Oligosaccharide Anions. Anal. Chem. 1993, 65(11), 1582-1587.

19. Carroll, J. A., Willard, D., Lebrilla, C. B. Energetics of Cross-Ring Cleavages and Their Relevance to the Linkage Determination of Oligosaccharides. Anal. Chim. Acta 1995, 307(2/3), 431-447. 
20. Fura, A.; Leary, J. A. Differentiation of $\mathrm{Ca}_{2}{ }^{+}-$Coordinated and $\mathrm{Mg}_{2}{ }^{+}-$ Coordinated Branched Trisaccharide Isomers-an Electrospray Ionization and Tandem Mass Spectrometry Study. Anal. Chem. 1993, 65(20), 2805-2811.

21. Garozzo, D., Impallomeni, G., Spina, E., Green, B. N., Hutton, T. Linkage Analysis in Disaccharides by Electrospray Mass-Spectrometry. Carbohydr. Res. 1991, 221, 253-257.

22. Mulroney, B.; Traeger, J. C.; Stone, B. A. Determination of Both Linkage Position and Anomeric Configuration in Underivatized Glucopyranosyl Disaccharides by Electrospray Mass Spectrometry. J. Mass Spectrom. 1995, 30(9), 1277-1283.

23. Zhu, J. H.; Cole, R. B. Ranking of Gas-Phase Acidities and Chloride Affinities of Monosaccharides and Linkage Specificity in CollisionInduced Decompositions of Negative Ion Electrospray-Generated Chloride Adducts of Oligosaccharides. J. Am. Soc. Mass Spectrom. 2001, 12(11), 1193-1204

24. Jiang, Y. J.; Cole, R. B. Oligosaccharide Analysis Using Anion Attachment in Negative Mode Electrospray Mass Spectrometry. J. Am. Soc. Mass Spectrom. 2005, 16(1), 60-70.

25. Mulroney, B.; Peel, J. B.; Traeger, J. C. Theoretical Study of Deprotonated Glucopyranosyl Disaccharide Fragmentation. J. Mass Spectrom. 1999, 34(8), 856-871.

26. Zaia, J. Mass Spectrometry of Oligosaccharides. Mass Spectrom. Rev. 2004, 23(3), 161-227.

27. Harvey, D. J. Matrix-Assisted Laser Desorption/Ionization Mass Spectrometry of Carbohydrates. Mass Spectrom. Rev. 1999, 18(6), 349-450.

28. Dell, A.; Morris, H. R. Glycoprotein Structure Determination Mass Spectrometry. Science 2001, 291(5512), 2351-2356.

29. Penn, S. G.; Cancilla, M. T.; Lebrilla, C. B. Collision-Induced Dissociation of Branched Oligosaccharide Ions with Analysis and Calculation of Relative Dissociation Thresholds. Anal. Chem. 1996, 68(14), 2331-2339.

30. Powell, A. K. Harvey, D. J Stabilization of Sialic Acids in N-Linked Oligosaccharides and Gangliosides for Analysis by Positive Ion MatrixAssisted Laser Desorption Ionization Mass Spectrometry. Rapid Commun. Mass Spectrom. 1996, 10(9), 1027-1032.

31. Nonami, H.; Fukui, S.; ErraBalsells, R. $\beta$-Carboline Alkaloids as Matrices for Matrix-Assisted Ultraviolet Laser Desorption Time-of-Flight Mass Spectrometry of Proteins and Sulfated Oligosaccharides: A Comparative Study Using Phenylcarbonyl Compounds, Carbazoles, and Classical Matrices. J. Mass Spectrom. 1997, 32(3), 287-296.

32. Nonami, H.; Tanaka, K.; Fukuyama, Y.; Erra-Balsells, R. $\beta$-Carboline Alkaloids as Matrices for UV-Matrix-Assisted Laser Desorption/Ionization Time-of-Flight Mass Spectrometry in Positive and Negative Ion Modes. Analysis of proteins of high molecular mass, and of cyclic and acyclic oligosaccharides. Rapid Commun. Mass Spectrom. 1998, 12(6), 285-296.

33. Nonami, H.; Wu, F. Y.; Thummel, R. P.; Fukuyama, Y.; Yamaoka, H.; Erra-Balsells, R. Evaluation of Pyridoindoles, Pyridylindoles, and PMyridylpyridoindoles as matrices for Ultraviolet Matrix-Assisted Laser Desorption/Ionization Time-of-Flight Mass Spectrometry. Rapid Commun. Mass Spectrom. 2001, 15(23), 2354-2373.

34. Wong, A. W.; Cancilla, M. T.; Voss, L. R.; Lebrilla, C. B. Anion dopant for Oligosaccharides in Matrix-Assisted Laser Desorption/Ionization Mass Spectrometry. Anal. Chem. 1999, 71(1), 205-211.

35. Cai, Y.; Jiang, Y. J.; Cole, R. B. Anionic Adducts of Oligosaccharides by Matrix-Assisted Laser Desorption/Ionization Time-of-Flight Mass Spectrometry. Anal. Chem. 2003, 75(7), 1638-1644.

36. Yamagaki, T.; Suzuki, H.; Tachibana, K. In-Source and Post-Source Decay in Negative-Ion Matrix-Assisted Laser Desorption/Ionization Time-of-Flight Mass Spectrometry of Neutral Oligosaccharides. Anal. Chem. 2005, 77(6), 1701-1707.

37. Yamagaki, T.; Suzuki, H.; Tachibana, K. Semiquantitative Analysis of Isomeric Oligosaccharides by Negative-Ion Mode UV-MALDI TOF Post-Source Decay Mass Spectrometry and Their Fragmentation Mechanism Study at N-Acetylhexosamine. J. Mass Spectrom. 2006, 41(4), $454-462$.

38. Yamagaki, T.; Suzuki, H.; Tachibana, K. A Comparative Study of the Fragmentation of Neutral Lacto-Oligosaccharides in Negative-Ion
Mode by UV-MALDI-TOF and UV-MALDI Ion-Trap/TOF Mass Spectrometry. J. Am. Soc. Mass Spectrom. 2006, 17(1), 67-74.

39. Spengler, B.; Kirsch, D.; Kaufmann, R. Metastable Decay of Peptides and Proteins in Matrix-Assisted Laser Desorption Mass Spectrometry. Rapid Commun. Mass Spectrom. 1991, 5(4), 198-202.

40. Spengler, B.; Kirsch, D.; Kaufmann, R.; Jaeger, E. Peptide Sequencing by Matrix-Assisted Laser-Desorption Mass-Spectrometry. Rapid Commun. Mass Spectrom. 1992, 6(2), 105-108.

41. Spengler, B.; Kirsch, D.; Kaufmann, R.; Lemoine, J. Structure-Analysis of Branched Oligosaccharides Using Post-Source Decay in Matrix-Assisted Laser Desorption Ionization Mass Spectrometry. Org. Mass Spectrom. 1994, 29(12), 782-787

42. Harvey, D. J.; Naven, T. J. P.; Kuster, B.; Bateman, R. H.; Green, M. R. Critchley, G. Comparison of Fragmentation Modes for the Structural Determination of Complex Oligosaccharides Ionized by MatrixAssisted Laser Desorption/Ionization Mass Spectrometry. Rapid Commun. Mass Spectrom. 1995, 9(15), 1556-1561.

43. Gibson, B. W.; Engstrom, J. J.; John, C. M.; Hines, W.; Falick, A. M. Characterization of Bacterial Lipo-Oligosaccharides by Delayed Extraction Matrix-Assisted Laser Desorption Ionization Time-of-Flight Mass Spectrometry. J. Am. Soc. Mass Spectrom. 1997, 8(6), 645-658.

44. Fukuyama, Y.; Ciancia, M.; Nonami, H.; Cerezo, A. S.; Erra-Balsells, R. Matulewicz, M. C. Matrix-Assisted Ultraviolet Laser Desorption Ionization and Electrospray Ionization Time-of-Flight Mass Spectrometry of Sulfated Neocarrabiose Oligosaccharides. Carbohydr. Res. 2002, 337(17), 1553-1562.

45. Talbo, G.; Mann, M. Aspects of the Sequencing of Carbohydrates and Oligonucleotides by Matrix-Assisted Laser Desorption/Ionization PostSource Decay. Rapid Commun. Mass Spectrom. 1996, 10(1), 100-103.

46. Zhu, J. H.; Cole, R. B. Formation and Decompositions of Chloride Adduct Ions, $[\mathrm{M}+\mathrm{Cl}](-)$, in Negative Ion Electrospray Ionization Mass Spectrometry. J. Am. Soc. Mass Spectrom. 2000, 11(11), 932-941.

47. Harvey, D. J. Fragmentation of Negative Ions from Carbohydrates: Part 1. Use of Nitrate and Other Anionic Adducts for the Production of Negative Ion Electrospray Spectra from N-Linked Carbohydrates. J. Am. Soc. Mass Spectrom. 2005, 16(5), 622-630.

48. Harvey, D. J. Fragmentation of Negative Ions from Carbohydrates: Part 2. Fragmentation of High-Mannose N-Linked Glycans. J. Am. Soc. Mass Spectrom. 2005, 16(5), 631-646.

49. Harvey, D. J. Fragmentation of Negative Ions from Carbohydrates: Part 3. Fragmentation of Hybrid and Complex N-Linked Glycans. J. Am. Soc. Mass Spectrom. 2005, 16(5), 647-659.

50. Vorm, O.; Roepstorff, P.; Mann, M. Improved Resolution and Very High-Sensitivity in MALDI TOF of Matrix Surfaces Made by Fast Evaporation. Anal. Chem. 1994, 66(19), 3281-3287.

51. Xiang, F.; Beavis, R. C. A Method to Increase Contaminant Tolerance in Protein Matrix-Assisted Laser Desorption Ionization by the Fabrication of Thin Protein-Doped Polycrystalline Films. Rapid Commun. Mass Spectrom. 1994, 8(2), 199-204.

52. Cai, Y.; Cole, R. B. Stabilization of Anionic Adducts in Negative Ion Electrospray Mass Spectrometry. Anal. Chem. 2002, 74(5), 985-991.

53. Guan, B.; Cole, R. B. Differentiation of Both Linkage Position and Anomeric Configuration in Underivatized Glucopyranosyl Disaccharides by Anion Attachment with Post-Source Decay in Matrix-Assisted Laser Desorption/Ionization Linear-Field Reflectron Time-of-Flight Mass Spectrometry. Rapid Commun. Mass Spectrom. 2007, 21(18), 31653168

54. Pfeifer, T.; Drewello, M.; Schierhorn, A. Using a Matrix-Assisted Laser Desorption Ionization Time-of-Flight Mass Spectrometer for Combined In-Source Decay/Post-Source Decay Experiments. J. Mass Spectrom. 1999, 34(6), 644-650.

55. Yamagaki, T.; Nakanishi, H. Ion Intensity Analysis of Post-Source Decay Fragmentation in Curved-Field Reflectron Matrix-Assisted Laser Desorption/Ionization Time-of-Flight Mass Spectrometry of Carbohydrates: For Structural Characterization of Glycosylation in Proteome Analysis. Proteomics 2001, 1(2), 329-339. 